\title{
Direitos sexuais, políticas públicas e educação sexual no discurso de pessoas com cegueira
}

Dalva Nazaré Ornelas França

\section{Resumo}

Este estudo objetiva analisar como pessoas com cegueira congênita percebem seu direito à sexualidade. Dele participaram onze pessoas com cegueira, de ambos os gêneros, com idades entre 22 e 54 anos, de duas instituições de apoio ao deficiente visual em Feira de Santana/Bahia. Realizaram-se entrevistas e sessões de grupo focal, analisadas qualitativamente, articulando dados empíricos e pressupostos das bioéticas. Emergiram três categorias: 1 . O direito à expressão da sexualidade, pouco respeitado; 2 . Avaliação das pessoas com cegueira, no tocante às políticas públicas voltadas para a sexualidade; 3 . Reflexões sobre educação sexual. Os resultados revelaram: sentimento de insatisfação, desrespeito da sociedade ao direito à sexualidade; consciência e necessidade de buscar seus direitos; políticas públicas escassas ou não acessíveis às pessoas com cegueira; necessidade de educação sexual adequada às suas condições. Concluímos que as pessoas cegas ainda se encontram invisíveis e vulneráveis. Defendemos a educação sexual como caminho para a inclusão social.

Palavras-chave: Sexualidade. Cegueira. Políticas públicas. Bioética.

\section{Resumen}

Los derechos sexuales, la política pública y el discurso sobre la educación sexual de las personas ciegas

Este estudio tiene por objeto examinar y analizar cómo las personas con ceguera congénita ejercen su derecho a la sexualidad. Once personas ciegas participaron, de ambos sexos, con edades comprendidas entre los 22 y los 54 años, inscritos en dos instituciones para apoyar a los discapacitados visuales en la ciudad de Feira de Santana/ Bahía. Fueron realizadas entrevistas y sesiones de grupo focales, analizadas cualitativamente, con la articulación de los datos empíricos y las hipótesis de la bioética. Surgieron tres categorías: 1 . El derecho a la expresión sexual, poco respetada, 2. Evaluación de los ciegos en cuanto a las políticas públicas dirigidas a la sexualidad, 3. Reflexiones sobre la educación sexual. Los resultados revelaron: sensación de insatisfacción, con poco respeto a su derecho de la sociedad al derecho a la sexualidad, la conciencia y la necesidad de buscar sus derechos, las políticas públicas escasas o no accesibles a la sexualidad del ciego; necesidad de una educación sexual adecuada a sus necesidades. Llegamos a la conclusión de que las personas ciegas siguen siendo invisibles a los ojos del Estado y de la sociedad, en una situación vulnerable. Seguimos en favor de la educación sexual como un camino hacia la inclusión social.

Palabras-clave: Sexualidad. Ceguera. Políticas públicas. Bioética.

\section{Abstract \\ Sexual rights, public policy and sex education on the discourse of blind people}

This study seeks to analyze how people with congenital blindness realize their right to sexuality. Eleven blind people participated, of both genders, aged between 22 and 54 years, enrolled in two institutions to support the visually impaired in the city of Feira de Santana/Bahia. There were interviews and focus group sessions, analyzed qualitatively, articulating empirical data and assumptions of bioethics. Three categories emerged: 1 . The right to sexual expression, little respected; 2 . Assessment of blind people regarding public policies focused on sexuality; 3 . Reflections on sex education. The results revealed: feeling of dissatisfaction, disrespect from society to sexual rights; awareness and need to seek their rights; scarce public policies or not accessible to the blind people; need for appropriate sex education to their needs. We conclude that blind people are still invisible and vulnerable. We advocate sex education as a path to social inclusion.

Key words: Sexuality. Blindness. Public policies. Bioethics.

Aprovação CEP UEFS n 119/2011

Doutoranda dnfranca@gmail.com - Faculdade de Medicina da Bahia, Universidade Federal da Bahia/Universidade Estadual de Feira de Santana/BA, Brasil.

Correspondência

Rua F, n 8, Conjunto ACM, Mangabeira CEP 44056-024. Feira de Santana/BA, Brasil.

Declara não haver conflito de interesse. 
A Organização Mundial da Saúde (OMS) classifica a deficiência visual em categorias que incluem desde a perda visual leve até a ausência total de visão. A Classificação Estatística Internacional de Doenças e Problemas Relacionados à Saúde (CID-10) define a cegueira em função da acuidade visual corrigida no melhor olho ${ }^{1}$. A Classificação Internacional de Funcionalidade, Incapacidade e Saúde (CIF) descreve a funcionalidade e a incapacidade relacionadas às condições de saúde, identificando o que uma pessoa pode ou não pode fazer na sua vida diária ${ }^{2}$, considerando as funções dos órgãos ou sistemas e estruturas do corpo, bem como as limitações de atividades e participação social no meio ambiente onde vive.

Em 2002, o Conselho Internacional de Oftalmologia associou critérios da CID-10 e da CIF e propôs uma classificação em categorias de deficiência visual, revista em 2003 em conjunto com a OMS. Sugere que o termo cegueira deve ser usado somente para a perda total da visão nos dois olhos e quando o indivíduo necessita de auxílios especiais para substituir suas habilidades visuais ${ }^{3}$. No presente estudo utilizaremos os termos cegueira e/ou pessoa cega nos referindo à cegueira congênita, com perda total de visão nos dois olhos.

De acordo com o Censo 2010, existem no Brasil 45,6 milhões de pessoas com alguma deficiência, representando $23,9 \%$ da população. A deficiência visual atinge 35,8 milhões, dos quais 506,3 mil são cegos - ou seja, $0,3 \%{ }^{4}$. Esse número significativo de pessoas merece atenção para que se busque conhecer a realidade por elas vivida em relação a seus direitos de cidadania.

A Constituição brasileira de 1988, no artigo 10, inciso III, elegeu o princípio da dignidade da pessoa humana como um dos fundamentos da República Federativa do Brasil ${ }^{5}$. A Declaração Universal sobre a Bioética e Direitos Humanos estabelece como princípio (artigo $3^{\circ}$ ) que a dignidade humana, os direitos humanos $e$ as liberdades fundamentais devem ser respeitadas em sua totalidade ${ }^{6}$. A Convenção sobre os Direitos das Pessoas com Deficiência tem por propósito promover, proteger e assegurar o exercício pleno e equitativo de todos os direitos humanos e liberdades fundamentais por todas as pessoas com deficiência, bem como promover o respeito pela sua dignidade inerente ${ }^{7}$, defendendo legalmente esses direitos conquistados. Apesar das garantias definidas nesses instrumentos, em nossa sociedade a expressão da sexualidade da pessoa com cegueira, e também a de outros deficientes, é carregada de preconceitos, estigmas e desigualdades que podem agravar sua situação de vulnerabilidade.
De acordo com Garrafa e Porto ${ }^{8}$, somente por meio do reconhecimento das diferenças e das necessidades diversas dos sujeitos sociais podemos alcançar a igualdade. Nessa perspectiva de reconhecer a sociedade em sua diversidade e pluralidade é que podemos, de fato, incluir socialmente todas as diferenças humanas. Desta forma, entendemos quanto é importante inserir essa temática - sexualidade das pessoas com cegueira - nas discussões bioéticas.

Nesse sentido, este trabalho busca refletir sobre os direitos, as políticas públicas e a educação sexual voltadas para as pessoas cegas, apoiado nos pressupostos defendidos pela bioética como dignidade, cidadania, autonomia, cuidado, tolerância, alteridade e outros - principalmente em uma bioética comprometida com as questões sociais das minorias negligenciadas. Para tanto, objetivou conhecer e analisar a percepção das pessoas com cegueira a respeito de seus direitos sexuais, a partir da experiência de frequentadores de duas instituições de apoio a pessoas com deficiência visual.

\section{Método}

Trata-se de estudo exploratório-descritivo, de natureza qualitativa. O projeto foi aprovado pelo Comitê de Ética em Pesquisa Envolvendo Seres Humanos da Universidade Estadual de Feira de Santana, Bahia. O estudo foi realizado com a participação voluntária de pessoas com cegueira congênita frequentadoras do Centro de Apoio Pedagógico ao Deficiente Visual da Fundação Jonathas Telles de Carvalho e da Associação Feirense de Deficiente Visual na cidade de Feira de Santana. Essas instituições foram selecionadas porque só nelas encontramos pessoas que atendessem aos critérios de inclusão da pesquisa.

Os critérios de inclusão foram: ser cego com diagnóstico de cegueira total até dois anos de idade; não apresentar outra deficiência associada à cegueira; ter mais de 18 anos e menos de 65 anos. Participaram da pesquisa seis homens e cinco mulheres, todos com cegueira congênita, com idades entre 22 e 54 anos e grau de instrução do ensino fundamental completo ao ensino superior incompleto.

Os dados foram coletados por entrevista individual semiestruturada a partir das seguintes questões norteadoras: Como você percebe o seu direito à expressão da sexualidade? Você acha que esse direito é respeitado? Após as entrevistas individuais foram realizadas três sessões de grupo focal como estratégia de complementação e percepção do comportamento grupal. 
A coleta de dados teve início em abril e término em julho de 2012. As entrevistas e as sessões de grupo focal foram realizadas nas instalações das duas instituições referidas, após os participantes concordarem em participar da pesquisa mediante a apresentação e assinatura do termo de consentimento livre e esclarecido (em Braille). Com o consentimento dos participantes, os dois procedimentos de coletas de dados foram gravados.

Para a identificação dos participantes utilizamos palavras referentes à sexualidade, de escolha dos mesmos, tais como: Elegante, Amorosa, Sensual, Carinhoso, Coração, Afetuosa, Apaixonada, Sedutor, Belo, Delicado e Comunicativo.

Após a transcrição das entrevistas e da sessão de grupo focal os dados foram submetidos à análise de conteúdo, que segundo Bardin ${ }^{9}$ é composta por uma sistematização de procedimentos objetivos de descrição do conteúdo de mensagens, bem como dos indicadores (quantitativos ou não) que possam levar à inferência das condições de produção e recepção destas mensagens. A análise aconteceu em três etapas: 1) leitura compreensiva buscando uma visão conjunta e a apreensão das particularidades das entrevistas e do material gerado no grupo focal, identificando os temas expressos nos depoimentos; 2) realização de recortes de trechos dos depoimentos, a partir de leitura horizontal que buscou identificar as ideias convergentes e diferentes dos participantes; 3) seguiu-se a leitura vertical para analisar como cada participante se manifestou frente aos temas que emergiram, evidenciando o que mais se repetia (expressões, palavras e frases) e que indicava conceitos e expressões teóricas sobre os direitos à expressão da sexualidade da pessoa cega, secundada pelo confronto entre os depoimentos individuais com os depoimentos do grupo. Finalmente, realizouse a articulação entre o material empírico (entrevista e grupo focal) e os referenciais teóricos da pesquisa, buscando responder as questões norteadoras, baseadas no objetivo proposto, daí advindo três categorias: 1- $O$ direito à expressão da sexualidade, pouco respeitado; 2- Avaliação das pessoas com cegueira, no tocante às políticas públicas voltadas para a sexualidade; 3- Reflexões sobre educação sexual.

\section{Resultados e discussão}

\section{Percepção de pouco respeito aos seus direitos}

Os direitos do exercício livre da sexualidade, paternidade e planejamento familiar são contemplados em vários documentos internacionais, como no artigo 16 da Declaração Universal dos Direitos Humanos: A partir da idade núbil, o homem e a muIher têm o direito de casar e de constituir família, sem restrição alguma de raça, nacionalidade ou religião ${ }^{10}$. Da mesma forma, a Convenção sobre os Direitos da Pessoa com Deficiência também garante, no artigo 23 , o direito à constituição de família, à paternidade, à informação adequada ao planejamento familiar: Os Estados Partes tomarão medidas efetivas e apropriadas para eliminar a discriminação contra pessoas com deficiência, em todos os aspectos relacionados a casamento, família, paternidade e relacionamento, em igualdade de condições com as demais pessoas ${ }^{7}$.

Entendemos também como direito à sexualidade o direito de viver e expressar livremente sem violência, discriminação e imposições e com respeito pleno pelo corpo do(a) parceiro(a); direito ao sexo seguro para prevenção da gravidez indesejada e de DST/HIV/Aids; direito a serviço de saúde que garanta privacidade, sigilo e atendimento de qualidade $e$ sem discriminação; e direito à informação e à educação sexual e reprodutiva ${ }^{11}$.

Apesar de o direito ao exercício da sexualidade das pessoas com deficiência constar de maneira geral ou específica nesses documentos oficiais, alguns participantes do estudo convergem na percepção de que seu direito à sexualidade é pouco respeitado: "O direito à sexualidade da pessoa cega é respeitado mais ou menos, não há esse respeito todo não... diria que há quem brinque com isso aí, sexualidade" (Sedutor). O preconceito também foi apontado pelos entrevistados como uma forma de não respeito aos seus direitos, como revela a fala a seguir: "Às vezes sim às vezes não, quando a pessoa tem preconceito com a pessoa cega ela não respeita o seu direito, tenta se afastar" (Amorosa).

De acordo com Anache ${ }^{12}$, a dificuldade de aceitação da cegueira por parte da sociedade pode trazer problemas para a inclusão social de pessoas com essa deficiência, vez que a inclusão é um processo complexo, que envolve mutuamente tanto a pessoa cega quanto o contexto que a cerca. Alguns participantes referiram-se a essa dificuldade aludindo à falta de compreensão da família, bem como da sociedade. Afirmam, porém, que o direito ao exercício da sexualidade, e dos demais direitos humanos, tem que ser buscado por cada um, como revelam os depoimentos a seguir:

"Há falta de compreensão das famílias, das pessoas em geral de aceitar a pessoa cega e respeitar sua sexualidade... Eu acho que não é respeitado nosso 
direito, agora a gente é que tem que procurar, cada dia mostrar que nós temos os mesmos direitos que as outras pessoas" (Elegante);

"A gente deficiente tem que se valorizar, não é ser melhor que os outros, é ser tão importante quanto os outros, eu acho que tem que ser dessa forma para superar os preconceitos" (Coração).

Mais uma vez o sentimento dessas pessoas é reforçado em relação à ausência de compreensão e respeito por sua sexualidade, evidenciando na busca dos seus direitos o papel da família e a necessidade do exercício da cidadania. A consciência da necessidade de buscar seus direitos pode estar refletindo a política de inclusão instituída no país, que impele essas pessoas a terem consciência de seus direitos e buscarem viver sua sexualidade livremente, apesar da discriminação e do preconceito social ainda vigente. Disso se pode depreender que, mesmo que não cumpram plenamente seu objetivo ou que em alguns aspectos deixem de focalizar os grupos específicos de pessoas com deficiência, como se verá a seguir, as políticas públicas da área podem ser conotadas como mecanismos de sensibilização social para as questões atinentes aos direitos dos portadores de deficiência.

Nesse sentido, para Rios ${ }^{13} \mathrm{o}$ direito democrático à sexualidade, enraizado nos princípios dos direitos humanos e nos direitos constitucionais fundamentais, deve atuar simultaneamente no sentido do reconhecimento do igual respeito às diversas manifestações da sexualidade e do igual acesso de todos, sem distinções, aos bens necessários para a vida em sociedade. No confronto das falas individuais e do grupo fica evidente o sentimento de insatisfação das pessoas cegas com o comportamento da sociedade em relação a sua sexualidade. Buscam justificar esse comportamento se referindo à falta de conhecimento sobre a pessoa cega e sua capacidade, não só no campo da sexualidade, mas em todos os campos da vida.

Fica nítido, portanto, que existe entre os participantes a consciência dos seus direitos e da necessidade de buscá-los com o objetivo de minimizar o preconceito; entendemos isso como uma atitude cidadã. Acreditamos que este ensejo manifesto pelos entrevistados pode ser o mecanismo capaz de fomentar a construção de moralidades capazes de respeitar as diferenças e se indispor com as injustiças, promovendo, dessa forma, a maternagem para com o outro ${ }^{14}$, na tentativa de minimizar o preconceito em relação à expressão da sexualidade das pessoas com cegueira. Tal atitude poderá ampliar o cuidar do outro numa perspectiva de equilíbrio da sociedade que se mostra unilateralizada, carente de cuidados e de serviços geradores de amorosidade.

Avaliação das pessoas cegas quanto às políticas públicas voltadas para a sexualidade

Todos os participantes foram unânimes em afirmar que não existem políticas públicas - relacionadas à sexualidade - voltadas para as pessoas cegas, como evidenciam esses depoimentos:

"Não ter política voltada para o cego é normal, a gente tenta fazer tudo da política em geral" (Comunicativa).

"Não tem... É um assunto pouco discutido, não se toca nesse assunto, é difícil" (Sensual).

"Eu acho que não tem facilidade os informativos, aqueles que têm para pessoas com deficiência são poucos a respeito da sexualidade, a pessoa tem que querer mesmo, porque ficar dependendo de informativo não aprende nada a respeito" (Apaixonada).

Apoiado na bioética de intervenção ${ }^{15}$, que propõe uma bioética comprometida politicamente com os mais necessitados e, ainda, o reconhecimento da responsabilidade social do Estado no propósito de promover e propiciar a libertação, empoderamento e emancipação dos indivíduos, grupos e populações vulneráveis ${ }^{14}$, infere-se ser dever do Estado proporcionar às pessoas cegas uma efetiva participação nas políticas voltadas para a sexualidade do deficiente. Embora existam iniciativas nesse sentido, como a política pública de saúde da pessoa portadora de deficiência, que contém diretrizes específicas pertinentes a atenção à saúde sexual e reprodutiva das pessoas com deficiência, como, por exemplo, a exortação para que se reconheça $o$ direito à expressão e vivência da sexualidade, abordando o tema sempre de forma criteriosa e ética, como parte da atenção à saúde sexual e reprodutiva ${ }^{16}$, tal estratégia não parece responder às necessidades e anseios das pessoas com deficiência visual.

Portanto, é urgente direcionar ações específicas para esse público, considerando-se sua impossibilidade de alcançar materiais informativos como folhetos, filmes e outros se não forem traduzidos para o Braille - linguagem acessível às pessoas cegas alfabetizadas no método. É também necessário considerar que podem existir pessoas cegas ainda não perfeitamente alfabetizadas em Braille, para as quais seria conveniente que também houvesse ou- 
tros tipos de material informativo, na forma de áudio, por exemplo, voltados a facilitar sua apreensão das informações. Assim, tal como pressupõe a bioética de intervenção, a política pública implementada por essas diretrizes poderia estimular uma atitude de libertação, que é aquela que promove políticas favoráveis aos vulneráveis (no caso, as pessoas cegas), no sentido de oferecer-lhes condições de expressão da sexualidade de forma segura e saudável.

Alguns participantes reportaram-se à falta de inclusão dos cegos nas políticas públicas voltadas para a prevenção das doenças sexualmente transmissíveis DST/HIV/Aids: "Não tem essa política, a política que tem ai é da DST/Aids que está para todo mundo, eles não se preocupam em explicar ao deficiente visual. Os órgãos públicos de saúde deveriam investir nessa área, mas a coisa é olhada com tanto desdém, com tanto descaso, que acho que pensam que cego não faz sexo" (Sedutor).

A vulnerabilidade dessas pessoas fica evidente nessa fala, que indica que o Estado ignora que esse grupo da população, que é sexualmente ativo e não recebe a devida atenção, fica vulnerável à contaminação e transmissão das DST/Aids.

Estudos realizados pelas organizações AidsFree World ${ }^{17}$ mostraram que pessoas com deficiência visual correm o risco de se infectarem com o vírus HIV em proporção duas vezes maior do que o restante da população. Diante disso, a ausência de políticas públicas adequadas às necessidades dos deficientes, apresentada nessa fala, configura-se como problemática à medida que se considera que o número de pessoas cegas no Brasil não é pequeno. Assim, a inexistência de informação acessível aos portadores de deficiência visual, por meio de políticas públicas adaptadas as suas necessidades, denota pouco respeito aos princípios éticos e epidemiológicos de saúde pública.

De acordo com Cordeiro e Pinto ${ }^{18}$, a pessoa com deficiência deve ser olhada pelo sistema de saúde como um sujeito autônomo e de direito, inclusive direitos sexuais e reprodutivos. No tocante ao deficiente visual, para que esses direitos sejam preservados e respeitados torna-se urgente a produção de materiais e o desenvolvimento de métodos de transmissão de conhecimento capazes de informar efetivamente, sem criar ou aumentar o constrangimento que, algumas vezes, cerca a discussão do tema. Além disso, é essencial a construção de uma rede de referência e contrarreferência entre os serviços de atenção à saúde da pessoa com deficiência e os especializados em DST/Aids, o que garantirá atendimento integral e equitativo.
É importante salientar, todavia, que desde 2006 o Programa Nacional de DST e Aids vem desenvolvendo debates com o objetivo de elaborar estratégias de integração do tema deficiência às ações de políticas públicas na área de promoção da saúde sexual e reprodutiva e de prevenção e atendimento às DST e HIV existentes no país. A partir desses debates foram extraídas recomendações para transversalização de temas na área de prevenção e de atendimento ao HIV/Aids em quatro eixos de ação: alianças; educação pública e comunicação; participação e empoderamento das pessoas com deficiência; e monitoração, avaliação e pesquisa ${ }^{19}$. Como visto, políticas públicas existem, porém não têm sido efetivas a ponto de atingir todos os deficientes, como relatado pelo participante.

No confronto entre as falas individuais e as do grupo focal foi também possível perceber que a questão da acessibilidade aos programas é contundente. Os entrevistados consideram que as políticas existem, mas não são acessíveis a eles. Relatam grande dificuldade até para obter no cotidiano outros direitos à saúde, como consultas e exames ginecológicos. Portanto, fica evidente a insatisfação dessas pessoas com o sistema de saúde, que consideram desrespeitoso a seus direitos de cidadania.

Gil e Meresman ${ }^{20}$ concordam com a percepção dos entrevistados, argumentando que as iniciativas voltadas à conscientização e prevenção de DST e do HIV/Aids dirigidas às pessoas com deficiência são pontuais (ou seja, de alcance restrito), esporádicas (não têm continuidade), raras vezes preservam a acessibilidade (usam linguagem e meios de comunicação inadequados ao público-alvo), não documentam o processo nem os resultados e não promovem o intercâmbio de informações entre os responsáveis por elas. Então, ante a percepção dos entrevistados e a análise dos especialistas, só se pode argumentar ser indispensável que a ação do Estado seja efetiva, tanto no sentido de consolidar o acesso aos serviços quanto de divulgar os programas existentes para assegurar a assistência aos portadores de deficiência. Além disso, pode-se inferir em sua fala a importância de aperfeiçoar esses programas, levando em consideração as peculiaridades dos diversos tipos de deficiências e sistematização da educação sexual destinada a essa parcela da população.

\section{Reflexões sobre a educação sexual}

Nos últimos anos, alguns pesquisadores têm se dedicado ao estudo da educação sexual e das 
deficiências, trazendo contribuições importantes para esclarecer à sociedade que essas pessoas têm as mesmas necessidades e direito de expressão da sexualidade como os demais cidadãos ${ }^{21-23}$. Os participantes do presente estudo apresentam ideias convergentes, considerando a importância da educação sexual para suas vidas: "Eu acho importante a educação sexual, porque assim nós vamos entender mais as coisas e tratar isso como uma coisa normal. Nós não íamos ser tão tímidos quando fosse tratar de coisas relacionadas à sexualidade, então eu acho isso muito bom" (Belo).

Este depoimento revela a necessidade que essas pessoas têm de ser reconhecidas como seres sociais em sua plenitude. Como qualquer indivíduo, necessitam encontrar espaço para realizar o desejo de amar e serem amadas, demonstrando capacidade de expressar sua sexualidade no meio social e alcançar suas aspirações, reprodutivas e de casamento, que constituem algo importante para a integração social. A afirmação da vida sexual resulta decisiva para o desenvolvimento da personalidade, principalmente durante a adolescência e a juventude, quando todos tentam demonstrar a si mesmos, e a quem Ihes rodeia, que são seres humanos desejosos da vida afetiva e sexual, como qualquer outra pessoa ${ }^{24}$.

Outro aspecto abordado foi a necessidade de a educação sexual para a pessoa cega iniciar-se desde a infância, como relata esse participante: "Educação sexual é muito importante, desde pequeno, quando eu era criança eu ficava analisando assim como era o órgão sexual das mulheres, a pessoa que enxerga ele olha uma criança ele já sabe como é, e sabe a diferença do órgão masculino e do órgão feminino e a criança cega não tem essa oportunidade de ver, é importante que ela saiba a diferença do órgão sexual masculino e feminino " (Elegante).

Não restam dúvidas de que as primeiras orientações para sexualidade devam acontecer no ambiente familiar, e as noções, que foram citadas, devem ser incorporadas de forma natural. Porém, quando se trata da sexualidade nem sempre a família colabora, pois envolve questões de tabu, vergonha e falta de conhecimento dos familiares.

Segundo Alzugaray e Alzugaray ${ }^{25}$, é fácil ocultar a realidade da criança cega; por exemplo, algumas pessoas vacilam em dar nomes às zonas genitais e não permitem que as crianças conheçam certas partes do corpo das outras pessoas, por exemplo. Assim, ela pode se enganar quanto ao tamanho, forma ou localização dos órgãos genitais. Por isso, é necessário familiarizá-la desde pequena com seu formato e função, tanto do próprio sexo como do sexo oposto. Tal procedimento poderá contribuir para a proteção dessas crianças contra possíveis abusos, minimizando suas vulnerabilidades.

É importante que os jovens e adultos com qualquer tipo de deficiência aprendam a conhecer o funcionamento de seu corpo e recebam informações adequadas no sentido de se protegerem de abusos, evitarem doenças sexualmente transmissíveis e viverem em plenitude os desejos afetivos e sexuais de forma socialmente aceita. Além das informações, é desejável que as pessoas cegas vivenciem a sexualidade como comportamento social expressando afetividade, libido e prazer ${ }^{26}$.

A educação sexual foi também apontada como um meio de adquirir conhecimentos específicos, possibilitando, assim, a quebra de preconceitos em relação à sexualidade dessas pessoas, conforme revela o depoimento a seguir: "Seria interessante, se tivesse educação sexual para ensinar mais, incentivar e quebrar mais o preconceito" (Amorosa). Se o preconceito é uma atitude favorável ou desfavorável, positiva ou negativa, anterior a qualquer conhecimento, e o estereótipo a concretização de um julgamento qualitativo, baseado no preconceito ${ }^{27}$, então a educação sexual para todos, incluindo as pessoas com deficiência, poderá contribuir para a inclusão social, amenizando o preconceito.

Os recursos didáticos facilitadores do processo ensino-aprendizagem também foram reivindicados pelos participantes da pesquisa, como revela o depoimento a seguir: "Interessante que tenha educação sexual para pessoas cegas, não precisa um método especial para os cegos, eles podem participar normalmente como qualquer outra pessoa, o que precisa é de material próprio e pronto... E aí a gente vai longe... [risos] (Comunicativa).

De fato, as pessoas cegas têm plena condição de compreender os conteúdos discutidos nas propostas de educação sexual dirigida às pessoas não cegas; o que falta é material adequado para atender suas necessidades. Alguns autores sugerem que para os deficientes visuais o ideal é o uso de objetos concretos que possam ser tocados, com texturas específicas, contornos e formas que facilitem a compreensão daquilo que se pretende explicar ${ }^{28,29}$. Assim, as pessoas com deficiência visual poderão adquirir conhecimentos sobre a sexualidade, possibilitando sua manifestação de forma segura e prazerosa.

No confronto das falas individuais e do grupo focal foi confirmada a percepção, pelos entrevistados, da necessidade de educação sexual que leve em consideração as limitações da pessoa cega, facilitan- 
do-lhe a aquisição de conhecimentos, contribuindo, assim, para o desenvolvimento pessoal e sexual.

\section{Considerações finais}

Apesar da existência de documentos oficiais que asseguram os direitos sexuais e reprodutivos das pessoas com deficiência, os participantes da pesquisa consideraram que esses direitos são pouco respeitados pela sociedade, porém demonstraram ter consciência dos mesmos e necessidade de buscá-los. Dialogamos sobre a necessidade de a sociedade agregar o valor da alteridade, proposto pela bioética de intervenção, que afirma só ser possível trabalhar com as diferenças se houver o reconhecimento do outro em toda a sua diversidade ${ }^{14}$. Somente desse modo os direitos dessas pessoas poderão ser respeitados em sua plenitude.

Embora existam políticas públicas voltadas para os direitos sexuais e reprodutivos, destinadas às pessoas com deficiência, as pessoas cegas não se sentem contempladas por elas, nem incluídas nos diversos programas, como o de prevenção das DST/ HIV/Aids. Entendemos ser dever do Estado direcionar ações no sentido de promover políticas públicas que protejam as pessoas em condição de vulnerabilidade, além de thes possibilitar o acesso aos serviços disponibilizados. Só por meio de uma política de saúde para todos é que poderemos tornar a sociedade de fato inclusiva.

As pessoas com deficiências não devem ser privadas da oportunidade de vivenciar sua sexualidade, de ter relações sexuais ou de ter filhos. Os estadosmembros devem promover a adoção de medidas destinadas a modificar as atitudes negativas perante o casamento, a sexualidade e a paternidade ou maternidade das pessoas com deficiências, em especial das jovens e das mulheres com deficiências ${ }^{30}$.

Entendemos que o caminho mais promissor para essa mudança de atitude seja mediante a educação sexual, apontada pelos participantes como algo importante e com perspectivas não só de adquirir conhecimento, mas, sobretudo, de reduzir o preconceito, pois não há necessidade de aulas especiais para pessoa cega, necessita-se apenas de recursos didáticos adaptados às suas efetivas necessidades. Assim agindo estaremos tomando medidas de proteção e, ao mesmo tempo, de promoção da autonomia, consequentemente incluindo as pessoas cegas. No dizer de Maia ${ }^{31}$, a sociedade inclusiva deveria ser um espaço em que a diversidade seja reconhecida em todas as suas dimensões sociais, inclusive em relação à sexualidade e à educação sexual, pois se trata de um direito de todos, também de populações com deficiências.

É nessa perspectiva que a bioética busca proporcionar reflexões no sentido de resgatar a dignidade e a cidadania dessas pessoas, apoiada nos pressupostos da autonomia, do cuidado, da tolerância, da alteridade, entre outros, que permeiam a discussão bioética e estão intrinsecamente relacionados às questões que envolvem a inclusão social, objetivando assegurar proteção à pessoa com deficiência, que se encontra em situação de vulnerabilidade, sem negar sua importância enquanto sujeito de direito. De acordo com Zoboli ${ }^{32}$, essa proteção tem de ser emancipadora para provocar a passagem da heteronomia moral para autonomia, condição própria e compatível com a dignidade e a liberdade humana. Desta forma poderemos encontrar caminhos para nos tornarmos uma sociedade de fato inclusiva, na qual a dignidade e as diferenças sejam respeitadas.

\section{Agradecimento}

À minha orientadora dra. Eliane S. Azevêdo, pela leitura e comentários ao presente trabalho.

\section{Referências}

1. Organização Mundial da Saúde. Classificação estatística internacional de doenças e problemas relacionados à saúde. 10ª ed. São Paulo: Edusp; 2003.

2. Centro Colaborador da Organização Mundial da Saúde para a Família de Classificações Internacionais, organizador. 2003. CIF: Classificação Internacional de Funcionalidade, Incapacidade e Saúde. São Paulo: Edusp; 2003.

3. Comunicado: a Diretoria do Conselho Brasileiro de Oftalmologia endossa a resolução abaixo, por estar ciente da relevância das informações nela contidas. Jornal Oftalmológico Jota Zero. [Internet]. 2003 (acesso 15 dez. 2012);(90). Disponível: www.cbo.com.br/publicações/jotazero/ ed90/comunicado.htm 
4. Instituto Brasileiro de Geografia e Estatística (IBGE). Censo demográfico 2010: características gerais da população, religiões e pessoas com deficiência. [Internet]. Rio de Janeiro: IBGE; 2010 (acesso 20 fev. 2013). Tabela 1.3.1. Disponível: ftp://ftp.ibge.gov.br/Censos/Censo_Demografico_2010/ Caracteristicas_Gerais_Religiao_Deficiencia/caracteristicas_religiao_deficiencia.pdf

5. Brasil. Constituição da República Federativa do Brasil. Brasília: Senado Federal; 1988.

6. Organização das Nações Unidas para a Educação, a Ciência e a Cultura (Unesco). Declaração Universal sobre Bioética e Direitos Humanos. Paris: Unesco; 2005

7. Brasil. Presidência da República. Secretaria Especial de Direitos Humanos. Coordenadoria Nacional para Integração da Pessoa Portadora de Deficiência. A Convenção sobre os direitos das pessoas com deficiência: versão comentada. [Internet]. $2^{\text {a }}$ ed. Brasília: Corde; 2008 (acesso fev. 2013). Disponível: http://www.adiron.com.br/site/uploads/File/ConvencaoComentada.pdf

8. Garrafa V, Porto D. Bioética, poder e injustiça: por uma ética de intervenção. Mundo Saúde. 2002;26(1):6-45.

9. Bardin L. Análise de conteúdo. Lisboa: Edições 70; 1997.

10. Organização das Nações Unidas. Declaração Universal dos Direitos Humanos. Adotada e proclamada pela resolução 217 A (III) da Assembleia Geral das Nações Unidas em 10 de dezembro de 1948. Washington: ONU; 2009.

11. Brasil. Ministério da Saúde. Secretaria de Atenção à Saúde. Direitos sexuais, direitos reprodutivos e métodos anticoncepcionais. Brasília: SAS; 2006. p. 4.

12. Anache AA. Educação e deficiência: estudo sobre a educação da pessoa com "deficiência" visual. Campo Grande: Cecitec/UFMS; 1994.

13. Rios RR. Para um direito democrático da sexualidade. Horiz Antropol. [Internet]. 2006 (acesso fev. 2013);12(26):71-100. Disponível: http://dx.doi.org/10.1590/S0104-71832006000200004

14. Gonçalves EH, Bandeira LM, Garrafa V. Ética e desconstrução do preconceito: doença e poluição no imaginário social sobre o HIV/Aids. Rev. bioét. (Impr.). 2011;19(1):159-78.

15. Garrafa V, Porto D. Intervention bioethics: a proposal for peripheral countries in a context of power and injustice. Bioethics. 2003;17(5-6):399-416.

16. Brasil. Ministério da Saúde. A pessoa com deficiência e o Sistema Único de Saúde. Brasília: Ministério da Saúde; 2006

17. Aids-Free World. Disabled Peoples' International. In: XVII International AIDS Conference; jul 2008; México. (acesso jan 2012). Disponível: http://www.aids-freeworld.org/content/view/177/66/

18. Cordeiro ID, Pinto AP. Aids e deficiências: os direitos humanos como interface. In: Brasil. Ministério da Saúde. Secretaria de Vigilância em Saúde. Programa Nacional de DST e Aids. Direitos Humanos e HIV/Aids: avanços e perspectivas para o enfrentamento da epidemia no Brasil. Brasília: Secretaria de Vigilância em Saúde/MS; 2008. p. 97-112. p. 104.

19. Brasil. Ministério da Saúde. Secretaria de Vigilância em Saúde. Programa Nacional de DST e Aids. Direitos humanos e HIV/Aids: avanços e perspectivas para o enfrentamento da epidemia no Brasil. [Internet]. Brasília: Secretaria de Vigilância em Saúde/MS; 2008 (acesso 1º dez. 2012). Disponivel: http://www.saude.gov.br/bvs

20. Gil M, Meresman S. Sinalizando a saúde para todos: HIV/Aids e pessoas com deficiência. Rede Saci. [Internet]. 15 dez. 2005 (1 mar 2013). Disponível: http://www.saci.org.br/index.php?modu lo $=$ akemi\&parametro $=17796$

21. Maia ACB. Sexualidade e deficiências. São Paulo: Editora Unesp; 2006.

22. Bruns MAT. Sexualidade de cegos. Campinas: Átomo; 2008.

23. Unbehaum S, organizadora. Sexualidade e deficiência visual: uma proposta de educação inclusiva. São Paulo: Ecos - Comunicação em Sexualidade/Fundação Dorina Nowill para cegos; 2009.

24. Castellano B, Gonzálea A. La sexualidad de los niños y adolescentes discapacitados: su atención e educación. In: IX Conferencia Cientifica LatinoAmericana de Educacion Especial. La Havana; 2000.

25. Alzugaray D, Alzugaray C. Enciclopédia da sexualidade. São Paulo: Oceano; 1995.

26. Paula AR, Sodelli FG, Faria G, Gil M, Regen M, Meresman S. Pessoas com deficiência: pesquisa sobre a sexualidade e vulnerabilidade. Temas sobre Desenvolvimento. 2010;17(98):51-65.

27. Amaral LA. Pensar a diferença: deficiência. Brasília: Corde; 1994.

28. Abreu TR. Um projeto de orientação sexual para adolescentes portadores de deficiência visual e deficiência auditiva. In: Anais do $2^{\circ}$ Encontro de Iniciação Científica; 25 ago. 2001; São Paulo. São Paulo: Ed. Mackenzie; 2001. p. 28.

29. Almeida TL, Baccheret SF. A elaboração de recursos técnicos para orientação sexual de deficientes visuais. In: Anais do $2^{\circ}$ Encontro de Iniciação Científica; 25 ago. 2001; São Paulo. São Paulo: Ed. Mackenzie; 2001. p. 179.

30. Schaaf M. Negociando sexualidade na Convenção de Direitos da Pessoa com Deficiência. Sur Revista Internacional de Direitos Humanos. 2011;8(14):115-35.

31. Maia ACB. Educação sexual e sexualidade no discurso de uma pessoa com deficiência visual. Revista Ibero-americana de Estudos em Educação. 2011;6(3):90-101.

32. Zoboli ELCP. Intersubjetividade e cuidado. In: Pessini L, Siqueira JE, Hossne WS, organizadores. Bioética em tempos de incertezas. São Paulo: Loyola; 2010. p. 357-74.

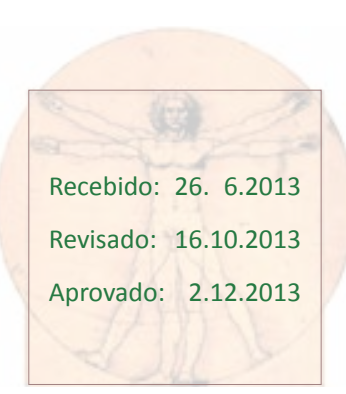

